\title{
Radiation Synthesis and Characterization of Polymeric Wet Adhesives for Attracting and Trapping Insects
}

Ahmed Awadallah-F ( $\nabla$ elsheshengy@yahoo.co.uk)

National Center for Radiation Research and Technology

M. A. Elhady

Egyptian Atomic Energy Authority

I. M. Mousaa

Egyptian atomic energy authority

\section{Research Article}

Keywords: Adhesive, Polyvinylpyrrolidone, Oleic acid, Cis-1,4-polyisoprene, Gamma Irradiation

Posted Date: May 17th, 2021

DOI: https://doi.org/10.21203/rs.3.rs-510784/v1

License: (c) (i) This work is licensed under a Creative Commons Attribution 4.0 International License.

Read Full License 


\section{Abstract}

Different blends are fabricated from oleic acid (OA), polyvinyl pyrrolidone (PVP), and cis-1,4-polyisoprene $(\mathrm{PI})$ are prepared at different ratios as wet adhesives for attracting and trapping insects. Different ratios of blends (PVP-PI)/OA are (1:2, 1:1 and 2:1 g/g), respectively. Ratio between PVP and PI is 9 to $1(\mathrm{~g} / \mathrm{g})$. The OA, PVP and PI are dissolved to form homogenous blends in all in-situ compositions. The blends were exposed to dose of 10 to $50 \mathrm{kGy}$. Adhesion properties, water sorption, Fourier transform infrared, thermogravimetric analysis and scan electron microscopy were conducted. The results showed that adhesion of all blends were augmented by increasing the irradiation dose up to $20 \mathrm{kGy}$. The best ratio of blend was 2:1 which contained high concentration of oleic acid. Blends (PVP-PI)/OA were tested to attract and trap flies and mosquitoes. Results confirmed good efficiency of (PVP-PI)/OA as wet adhesives for attracting and trapping flies and mosquitoes.

\section{Introduction}

When two dry surfaces are put into contact, instant adhesion may take place, due tohydrogen bonds, physical entanglements, electrostatic and van der Waals interaction $\left[{ }^{1},{ }^{2}\right]$. If interfacial water existed on one side or both sides of surfaces, the aforementioned interactions are significantly restricted as the interfacial water separates molecules from the two sides of surfaces $\left[{ }^{3},{ }^{4}\right]$. Wet adhesion of surfaces with interfacial water, however, is of remarkable importance in a wide range of biomedical and industrial fields such as bioadhesives for wet tissues and underwater glues $\left[{ }^{5,}, 6\right.$. A widely utilized approach for adhesion of wet surfaces such as wet tissues depends basically on a diffusion-based mechanism. Assuming that the adhesive constituents (e.g., monomers, oligomers, macromers, polymers, particles, etc.) from the adherend $\boldsymbol{A}$ (as one side surface) can diffuse through the interfacial water to form physical and/or covalent crosslinking on the surface of or within the adherend $\boldsymbol{B}$ (as the other side surface) $\left.{ }^{7}, 8\right]$. Further, this diffusion-based mechanism can bond the wet surfaces, the diffusion of adhesive constituents typically needs a relatively long time is due of weak diffusivity of huge molecules [ $\left.{ }^{9}\right]$. There are commercially available bioadhesives usually take short time (a few minutes) to adhere to wet tissues [ $\left.{ }^{10}\right]$. Adhesive pads on the legs of insects have attracted the biologists for decades [ $\left.{ }^{11},{ }^{12}\right]$. Insect adhesive organs characterize with amazing composition diversity and impressive functioning [ $\left.{ }^{13}\right]$. Some insects are able to resist the disconnection forces equivalent to more than 100 times their own body weight on smooth surfaces and yet able to run on these substrates $\left[{ }^{14}, 15\right]$. Nonetheless, the mechanism of how they control the conflicting tasks of running and of making stable adhesive contacts is still mostly not identified [ ${ }^{16}$ ]. Recently, it was reported from literature that a certain work was developed some tough hydrogel adhesives and topological adhesion $\left[{ }^{17}, 18\right]$. The results showed that the steady compression of adherents were for 5 to 30 minutes to form stable adhesion $\left[{ }^{19}\right]$. It is noteworthy to mention that the hydrogels are cross-linked hydrophilic polymer networks that can swell but does not dissolve in water and retain significant amount of water in their structures $\left[{ }^{20}\right]$. The ability of water absorption is due to hydrophilic nature of functional groups such as alcohols, carboxyls, sulphonic acid, etc on the polymer 
backbone $\left[{ }^{21}\right]$. The cross-linking of hydrophilic polymers/monomers can carry out the synthesis of hydrogel, and cross-linking can be done either by chemical approach or by radiation approach $\left[{ }^{22}\right]$. In radiation processing technology initiator, catalyst and cross linker is not required because the ionizing radiation is highly energetic $\left[{ }^{23}\right]$.

Overall, the radiation approach depends basically on the utilization of high energy ionizing radiation to initiate chemical and/or biological changes and modifications in the respective component. lonizing radiation techniques are being used for synthesis of gels, functional polymers, interpenetrating constituents, chemical/physical modification on a certain surface, immobilization of bioactive agent, functionalization process, etc $\left[{ }^{24}\right]$. The radiation processing technique has numerous advantageous features like easy process control, simultaneous crosslinking of polymer to hydrogel preparation and sterility of the final synthesized hydrogels, and the technology is environmentally-friendly and no residue or pollutant in the surrounding environment $\left.{ }^{25}\right]$. Plus, it is no need to add initiators, crosslinkers, no waste and relatively low running costs $\left[{ }^{26}\right]$. In addition, the ionizing radiation has been since long identified as a very convenient approach for the fabrication of hydrogels. Insect traps are a class of ex-farm add-ons that are very effective at countering herbivore insects. These can target certain species without harming the ecology of an area, irrespective of how crops are raised [ $\left.{ }^{27}\right]$. The type of adhesive used on a trap can also be an important factor influencing trap capture of insects. Relatively few studies examine this, but those that do indicate that different adhesives can catch different numbers of insects, for example Cicadellidae $\left[{ }^{28}\right]$, Diptera $\left[{ }^{29}, 30\right]$, and Aleyrodidae $\left[{ }^{31}\right]$. Conversely, trapping efficiency of the psyllid Diaphorina citri Kuwayama or the tephritid fly Rhagoletis indifferens Curran was not affected by adhesives $\left[{ }^{32}, 33\right]$.

Authors suggest synthesizing sticky crosslinked materials to trap the some insects. Therefore, the aim of this work is to synthesize and characterization of wet adhesives form from different constituents; PVP, PI and $O A$ with different ratios. The technology of ionizing irradiation (i.e., g-rays) can be used to prepare different crosslinked blends as wet adhesives. Moreover, the various tools are utilized to characterize the outcome products such FTIR, TGA and SEM. Further, the adhesion force is measured at different ratios of formed wet adhesive products. Furthermore, these wet adhesive products can be exploited to attract and trap the insects such as flies and mosquitoes as well.

\section{Materials And Methods}

\section{Materials}

Polyvinyl pyrrolidone (PVP) 90 kDa, cis-1,4-polyisoprene (97\% cis-1,4) (PI) and oleic acid (OA) (assay $\geq$ 99\%) were purchased from Sigma-Aldrich (Germany). Smooth white cardboard papers (dimensions of 20 $\mathrm{cm}$ width ' 30 length $\mathrm{cm}$ ' $0.2 \mathrm{~cm}$ thickness) were purchased from Guangzhou Keerun paper company (Guangdong, China). Glass test tubes with cork stoppers (dimensions of $30 \mathrm{~mm}$ ' $200 \mathrm{~mm}$ ) were supplied 
from Shandong Liquorpac company (China). Water level measuring tool was supplied from China (model number:lyh-12).Other reagents are used as received without further purification.

\section{Preparation of homogenous and crosslinked blend}

Different ratios of PVP to PI are blended together from 1:9 and 9:1 $(\mathrm{g} / \mathrm{g})$ using electric laboratory mixer of $200 \mathrm{rpm}$ for $10 \mathrm{~min}$ at room temperature as listed in Table 1. It was noticed after mixing the wide range ratios of PVP to PI that the optimum composition (completely homogeneous blend) is at a certain one of 9 to1 of PVP to $\mathrm{PI}$, respectively. This ratio represents the critical composition. Further, this ratio will be named hereafter as PVP9-PI1 (see other coded samples in Table 1). OA was added to PVP9-PI1. Different ratios of PVP9-PI1 to AO are 1:2, 1:1 and 2:1 (g/g), respectively. These ratios were mixed using electric laboratory mixer of $200 \mathrm{rpm}$ at $70{ }^{\circ} \mathrm{C}$ for $5 \mathrm{~min}$ to form homogenous liquid blends. These homogenous liquid blends were poured into glass test tubes followed by purging with nitrogen gas for 2 min of flow rate $100(\mathrm{ml} / \mathrm{min})$ then closed carefully. Then, these homogenous liquid blends were exposed to gamma irradiation at different irradiation doses ranged from 10 to $50 \mathrm{kGy}$ of dose rate $\sim 2.2 \mathrm{kGy} / \mathrm{h}$. The symbols of coded outcome samples are listed in Table 1. The emerged samples after irradiation process were extracted and casted in new glass bottles. Further, the extracted final products are viscous liquids and featured with yellow color. The proposed reaction mechanism of homogenous and crosslinked blend formation of PVP, PI and OA from PVP, PI and AO constituents are schematized in Figure 1.

Table 1. Exposes the optimum conditions of homogenous mixture formation of PVP and PI and different compositions of (PVP/PI) to OA for wet adhesives. 


\begin{tabular}{|c|c|c|c|c|c|}
\hline Sample code & \multicolumn{2}{|c|}{$\begin{array}{l}\text { PVP:PI ratio } \\
(\mathrm{g} / \mathrm{g})\end{array}$} & \multicolumn{3}{|c|}{ Notice } \\
\hline PVP9-PI1 & \multicolumn{2}{|l|}{$9: 1$} & \multicolumn{3}{|c|}{ completely mixed } \\
\hline PVP8-PI1 & \multicolumn{2}{|l|}{$8: 1$} & \multicolumn{3}{|c|}{ partially separated } \\
\hline PVP7-PI1 & \multicolumn{2}{|l|}{$7: 1$} & \multicolumn{3}{|c|}{ separated } \\
\hline PVP6-PI1 & \multicolumn{2}{|l|}{$6: 1$} & \multicolumn{3}{|c|}{ separated } \\
\hline PVP5-PI1 & \multicolumn{2}{|l|}{$5: 1$} & \multicolumn{3}{|c|}{ separated } \\
\hline PVP4-PI1 & \multicolumn{2}{|l|}{$4: 1$} & \multicolumn{3}{|c|}{ separated } \\
\hline PVP3-PI1 & \multicolumn{2}{|l|}{$3: 1$} & \multicolumn{3}{|c|}{ separated } \\
\hline PVP2-PI1 & \multicolumn{2}{|l|}{$2: 1$} & \multicolumn{3}{|c|}{ separated } \\
\hline PVP1-PI1 & \multicolumn{2}{|l|}{$1: 1$} & \multicolumn{3}{|c|}{ separated } \\
\hline PVP1-PI2 & \multicolumn{2}{|l|}{$1: 2$} & \multicolumn{3}{|c|}{ separated } \\
\hline PVP1-PI3 & \multicolumn{2}{|l|}{$1: 3$} & \multicolumn{3}{|c|}{ separated } \\
\hline PVP1-PI4 & \multicolumn{2}{|l|}{$1: 4$} & \multicolumn{3}{|c|}{ separated } \\
\hline PVP1-PI5 & \multicolumn{2}{|l|}{$1: 5$} & \multicolumn{3}{|c|}{ separated } \\
\hline PVP1-PI6 & \multicolumn{2}{|l|}{$1: 6$} & \multicolumn{3}{|c|}{ separated } \\
\hline PVP1-PI7 & \multicolumn{2}{|l|}{$1: 7$} & \multicolumn{3}{|c|}{ separated } \\
\hline PVP1-PI8 & \multicolumn{2}{|l|}{$1: 8$} & separ & ted & \\
\hline PVP1-PI9 & $1: 9$ & & separ & ted & \\
\hline Sample code & $\begin{array}{l}\text { PVP:PI } \\
(\mathrm{g} / \mathrm{g})\end{array}$ & $\begin{array}{l}(\mathrm{PVP} / \\
(\mathrm{g} / \mathrm{g})\end{array}$ & & $\begin{array}{l}\text { Dose } \\
\text { (kGy) }\end{array}$ & $\begin{array}{l}\text { Dose rate } \\
\mathrm{kGy} / \mathrm{h}\end{array}$ \\
\hline (PVP9-PI1)1/OA2-10 & $9: 1$ & $1: 2$ & & 10 & 2.15 \\
\hline (PVP9-PI1)1/OA2-20 & & & & 20 & \\
\hline (PVP9-PI1)1/OA2-30 & & & & 30 & \\
\hline (PVP9-PI1)1/OA2-40 & & & & 40 & \\
\hline (PVP9-PI1)1/OA2-50 & & & & 50 & \\
\hline (PVP9-PI1)1/OA1-10 & $9: 1$ & $1: 1$ & & 10 & 2.15 \\
\hline (PVP9-PI1)1/OA1-20 & & & & 20 & \\
\hline
\end{tabular}




\begin{tabular}{|c|c|c|c|c|}
\hline (PVP9-PI1)1/OA1-30 & & & 30 & \\
\hline (PVP9-PI1)1/OA1-40 & & & 40 & \\
\hline (PVP9-PI1)1/OA1-50 & & & 50 & \\
\hline (PVP9-PI1)2/OA1-10 & \multirow[t]{5}{*}{$9: 1$} & \multirow[t]{5}{*}{$2: 1$} & 10 & \multirow[t]{5}{*}{2.15} \\
\hline (PVP9-PI1)2/OA1-20 & & & 20 & \\
\hline (PVP9-PI1)2/OA1-30 & & & 30 & \\
\hline (PVP9-PI1)2/OA1-40 & & & 40 & \\
\hline (PVP9-PI1)2/OA1-50 & & & 50 & \\
\hline
\end{tabular}

\section{Water sorption}

Water sorption (WS) is estimated via utilizing numerous samples of crosslinked blends. The WS is carried out in distilled water at ambient temperature. Moreover, the crosslinked blends were immersed at various interval times using a balance (Adam Equipment, PW254 Laboratory Balance with an accuracy of $0.1 \mathrm{mg}$ ) The WS can be estimated from Eq.1 [ $\left.{ }^{34}\right]$

$W S(\%)=W_{0}-W_{t} / W_{0}{ }^{\prime} 100$

whereas the $W_{0}$ and $W_{t}$ are weights of dry and wet samples at a certain time (h), respectively.

\section{Adhesion force measurement}

The crosslinked (PVP-PI)/OA blend is poured on the surface of $1 \mathrm{~cm}$ of width ' $1 \mathrm{~cm}$ of length (note that the original dimensions of smooth card paper are $1 \mathrm{~cm}$ of width ' $10 \mathrm{~cm}$ of length). The above poured (PVP-PI)/OA blend on $1 \mathrm{~cm}^{\prime} 1 \mathrm{~cm}$ was covered by $1 \mathrm{~cm}$ of width ' $10 \mathrm{~cm}$ of length. The covering scale from two sides is only on $1 \mathrm{~cm}^{\prime} 1 \mathrm{~cm}$ and the crosslinked (PVP-PI)/OA blend is like a sandwich between two sides of papers. These samples are left for $5 \mathrm{~min}$ in the former position to let the two sides of papers sticking well on the crosslinked (PVP-PI)/OA blend. The crosslinked (PVP-PI)/OA blend ratios of 1:2, 1:1 and $2: 1(\mathrm{~g} / \mathrm{g})$ are conducted utilizing a wide range of irradiation dose, 10 to $50 \mathrm{kGy}$. The adhesive force is estimated using the mechanical device. The measurements of the mechanical properties of blends were estimated by a microprocessor controlled tensile testing apparatus of (Hung-Ta Model HT-9112, Taiwan).

\section{Attraction and trapping insects}

Glass sheet with dimensions (length $20 \mathrm{~cm}$ ' width $30 \mathrm{~cm}$ ' thickness $1 \mathrm{~mm}$ ) were cleaned up carefully with distilled water followed by ethanol then was put on the clean bench. The clean glass sheets were balanced using water level measuring tool. The cardboard paper was put onto the clean surface of glass sheet and adjusted well to fit the glass sheet's dimensions. The cardboard paper was adjusted on the 
surface of film applicator (Elcometer 3520 Baker Film Applicator). The crosslinked (PVP-PI)/OA blend were poured slowly and attentively onto the surface of film applicator that was adjusted at $200 \mathrm{~mm}$. The casted blend is left to spread and cover the whole card paper surface. Thereafter, the casted blend on card paper is left to be in open air for 15 min (one time in day light of Lab and other time in night darkness in Lab) in order to attract and trap the insects. Moreover, the ratios of (PVP-PI)/OA employed are 1:2, 1:1 and 2:1 (g/g), respectively. The range of dose is from 10 to $50 \mathrm{kGy}$ for each ratio of (PVP-PI)/OA blend as listed in Table 1. The set-up of casting process for the crosslinked (PVP-PI)/OA blend for attracting and trapping insects (e.g., flies, mosquitoes, etc) is shown in Figure 2.

\section{Characterizations}

The FTIR spectra were conducted by a Nicolet Avatar 320 FTIR Spectrophotometer in the range of 4000$400 \mathrm{~cm}^{-1}$ with 60 scan. The surface morphologies of the crosslinked (PVP-PI)/OA blends were carried out by Scanning electron Microscope (SEM), JSM-5400, JEOL Ltd., Tokyo, Japan. Thermal Gravimetric Analysis (TGA, Q50) measurements were performed in a TA Instruments thermal analyzer, at heating rate of $10^{\circ} \mathrm{C} / \mathrm{min}$, under bubbling nitrogen gas.

\section{Results And Discussion}

Figure 3 displays the spectra of three compositions of the crosslinked (PVP9-PI1)/OA blends. These compositions are 2:1. 1:1 and 1:2 (g/g), respectively at $30 \mathrm{kGy}$ and with dose rate is $\sim 2.2 \mathrm{kGy} / \mathrm{h}$. It can be observed that the characteristic bands of oleic acid are stretching band of $\mathrm{C}=0\left(1720 \mathrm{~cm}^{-1}\right)$, the strong band of $\mathrm{CH}_{2}$ groups for asymmetric and symmetric are 2935 and $2850 \mathrm{~cm}^{-1}$, respectively. Further, The broad peak in the $3070 \mathrm{~cm}^{-1}$ region is due to the $\mathrm{O}-\mathrm{H}$ stretching of carboxylic acid groups (-COOH) [35]. As it can be observed that the characteristic peaks of PVP are $\mathrm{C}-\mathrm{H}$ bending and $\mathrm{CH}_{2}$ wagging were seen at $1432 \mathrm{~cm}^{-1}$ and $1263 \mathrm{~cm}^{-1}$, respectively [36]. The peaks at 1081 and $562 \mathrm{~cm}^{-1}$ were identified as the $\mathrm{CH}_{2}$ rock and $\mathrm{N}-\mathrm{C}=\mathrm{O}$ bending, respectively [36]. The characteristic peak of $\mathrm{PI}$ is 1,4-cis units $(\mathrm{CH}$ group in $=\mathrm{C}-$ $\mathrm{H})$ appeared at $831 \mathrm{~cm}^{-1}\left[{ }^{37}, 38\right]$. Overall, the three compositions of the crosslinked (PVP9-PI1)/OA blends are similar and different only in intensity of peaks. In addition, it can be noticed that the $\mathrm{C}=\mathrm{C}$ either $\mathrm{PI}$ or OA in all compositions disappeared completely from spectra of crosslinked (PVP9-PI1)/OA blends (see Fig.S1 in Supplementary Data File).

Figure 4 exposes the relationship between the time (h) and WS (\%) of three compositions of crosslinked (PVP9-PI1)/OA blends; 2:1, 1:1 and 1:2 (g/g), respectively at exposure irradiation dose is $30 \mathrm{kGy}$ of irradiation dose rate is $\sim 2.2 \mathrm{kGy} / \mathrm{h}$. Overall, it can be observed that by augmenting the feeding of PVP into the blend, the WS (\%) increases. This is due to the hydrophilic affinity of PVP to absorb water $\left.{ }^{39}\right]$. Further, the existence of $\mathrm{PI}$ and $\mathrm{OA}$ is hydrophobic and lead to decrease the WS (\%) $\left[{ }^{40}\right]$.

Figure 5 illustrates TGA of three compositions of the crosslinked (PVP9-PI1)/OA blends (a) 2:1. (b) 1:1 and (c) $1: 2(\mathrm{~g} / \mathrm{g})$, respectively at exposure irradiation dose is $30 \mathrm{kGy}$ of irradiation dose is $\sim 2.2 \mathrm{kGy} / \mathrm{h}$. Overall, it can be noticed that by augmenting the amount of OA the thermal stability of the crosslinked 
(PVP9-PI1)/OA blend decreases. Further, the thermogram curves indicate to the thermal decomposition occurs at three stage of temperatures is around $35-113,115-265$ and $313-565^{\circ} \mathrm{C}$ for assigned to the evaporation of humidity, side function groups and backbone, respectively. The melting point of OA is from 13 to $14{ }^{\circ} \mathrm{C}\left[{ }^{41}\right]$, the melting temperature of $\mathrm{PI}$ is from 55.4 to $60^{\circ} \mathrm{C}\left[{ }^{42}\right]$ and melting temperature of PVP is from 150 to $180^{\circ} \mathrm{C}\left[{ }^{43}\right]$. Thus, the thermal stability of all outcome mixtures are lower than PVP and higher than $\mathrm{PI}$ and $\mathrm{OA}$. Because $\mathrm{PI}$ and $\mathrm{OA}$ are in liquid states featured with low melting temperatures. Therefore, they are easy to thermally decompose than all mixtures.

Figure 6 exposes the SEM photomicrographs of three compositions of crosslinked (PVP9-PI1)/OA blends at (a) 2:1. (b) 1:1 and (c) 1:2 (g/g), respectively at exposure irradiation dose is $30 \mathrm{kGy}$ of irradiation dose rate is $\sim 2.2 \mathrm{kGy} / \mathrm{h}$. Further, the SEM photomicrographs displayed that the difference in morphology among samples. This difference is due to the sample composition.

Figure 7 shows the influence of irradiation dose on the adhesion forces at three different compositions of crosslinked (PVP9-PI1)/OA blends at 2:1. (b) 1:1 and (c) 1:2 (g/g), respectively at irradiation dose rate is $2.2 \mathrm{kGy} / \mathrm{h}$. Overall, it can be noticed that the adhesion force of crosslinked (PVP9-PI1)/OA blends at 2:1. (b) $1: 1$ and (c) 1:2 (g/g) augments by augmenting the irradiation dose up to $20 \mathrm{kGy}$ and then started to lessen. Thus, the highest irradiation dose is $20 \mathrm{kGy}$ represents the highest adhesion force for all compositions. In addition, the adhesion force boosts by raising the $\mathrm{OA}$ into the content of in-situ blend (before irradiation). Therefore, it can be realized that by increasing irradiation dose leads to increase the crosslinking density of formed gels. Consequently, it can enhance the adhesion force. Further, the augmenting of $\mathrm{OA}$ acid leads to enhance the adhesion force. This may be due to increasing crosslinking density by opening its double bonds. It is noteworthy to mention that the fitting parameters and their formulas are written down in Table 2. These parameters clarify the relationship between the exposure irradiation dose and (kGy) and adhesion force ( $\mathrm{kPa})$. Through the listed results in Table 2, it can be deduced that there is a good relationship between the exposure irradiation dose and adhesion force based on correlation coefficient value.

Table 2. Displays the fitting parameters and their formulas of relationship between the exposure irradiation dose and adhesion force

\begin{tabular}{|c|c|c|c|c|c|c|}
\hline \multirow[t]{2}{*}{ Sample } & \multicolumn{5}{|c|}{ Fitting parameters } & \multirow[t]{2}{*}{ Formula ${ }^{* *}$} \\
\hline & a & b & c & d & $\mathbf{R}^{2}$ & \\
\hline (PVP9-PI1)2/OA1 & 0.01 & -1.54 & 41.01 & -74.70 & 0.90 & \multirow[t]{3}{*}{$f=a \chi^{3}+b \chi^{2}+c \chi+c$} \\
\hline (PVP9-PI1)1/OA1 & 0.01 & -1.19 & 25.41 & 197.38 & 0.91 & \\
\hline (PVP9-PI1)1/OA2 & 9.99 & -1.10 & 30.27 & 192.37 & 0.93 & \\
\hline
\end{tabular}


Figure $\mathbf{8}(\mathrm{a}, \mathrm{b})$ illustrates the adhesion force efficiency of three compositions of crosslinked (PVP9-PI1)/OA blends at 2:1, 1:1 and 1:2 (g/g) versus time and temperature, respectively. Overall, it can be seen from Fig.8a that the value of adhesion force for three compositions of crosslinked (PVP9-PI1)/OA blends at 2:1,1:1 and $1: 2(\mathrm{~g} / \mathrm{g})$ versus time starting from 1 day to 460 day almost did not change. Therefore, the stability of these wet adhesives is very good for long period of time as depicted previously. Moreover, It can be observed from Fig.8b that the adhesion force efficiency of three compositions of crosslinked (PVP9-PI1)/OA blends at 2:1, 1:1 and $1: 2(\mathrm{~g} / \mathrm{g})$ against temperature that ranged from 4 to $35^{\circ} \mathrm{C}$ is almost stable on whole range of temperature used. Consequently, the adhesion force efficiency of three compositions is very good at different range of temperature.

Figure 9 (a-c) displays the photos of adhesion force of crosslinked (PVP9-PI1)/OA blend at various angles $45^{\circ}, 90^{\circ}$ and $180^{\circ}$, respectively for composition of blend at $1: 2(\mathrm{~g} / \mathrm{g})$, irradiation dose $20 \mathrm{kGy} / \mathrm{h}$ and irradiation dose rate is $\sim 2.2 \mathrm{kGy} / \mathrm{h}$. This ratio was chosen from outcome results to symbolize the best sample of adhesion force. Moreover, through the observation it can be assuming that this adhesive of sample is flexible can be stretched into different angles such as $45^{\circ}, 90^{\circ}$ and $180^{\circ}$ without damage in adhesive content.

Figure 10 shows the attracting and trapping of flies and mosquitoes utilizing various samples such as PVP, PI, OA, (PVP9-PI)1/OA2 and (PVP9-PI)2/OA1, (PVP9-PI)2/OA1-20, (PVP9-PI)1/OA1-20. It can be observed that PVP, PI, OA, (PVP9-PI)1/OA2 and (PVP9-PI)2/OA1 have no impact to attract or trap either flies or mosquitoes. Additionally, the two compositions of crosslinked (PVP9-PI1)/OA blends are the lowest and the highest ratios of (PVP9-PI1)2/OA1-20 and (PVP9-PI1)1/OA2-20, correspondingly. During the observations into the photos of attracted and trapped flies and mosquitoes, it can be noticed that the number of either flies or mosquitoes augments by augmenting the quantity of OA that existed in-situ synthesis of blends. These numbers of attracted and trapped flies or mosquitoes are within time of 15 min. General observation from Fig.10 indicates to the number of the flies and mosquitoes are small in (PVP9-PI1)2/OA1-20 and huge number in case of crosslinked blends (PVP9-PI1)1/OA2-20. Further, the sample was put in open air (Authors' Laboratory) through daylight to attract and trap the flies and put the same sample in dark of open air (Authors' Laboratory) to attract and trap the mosquitoes. It is interesting to say the three constituents are mixed together before irradiation has no influence to attract and trap either mosquitoes or flies and the same three constituents are mixed together and exposed to gamma irradiation exposed a significant influence on catching the mosquitoes and flies as well.

\section{Conclusions}

In this work, wet adhesive was synthesized from PVP, PI and OA utilizing of wide range of gamma irradiation dose; 10 to $60 \mathrm{kGy}$ of dose rate $\sim 2.2 \mathrm{kGy} / \mathrm{h}$. The wet adhesives were prepared from three ratios of (PVP-PI)/OA are 2:1, 1:1 and 1:2 g/g, correspondingly. Moreover, the ratio of PVP to PI ranged from 1 to 9 and from 9 to $1(\mathrm{~g} / \mathrm{g})$. The results referred to that the optimal ratio was $9(\mathrm{~g})$ of PVP to $1(\mathrm{~g})$ PI. The outcome wet adhesives were identified by various techniques such as FTIR, TGA, SEM and adhesion 
force. Additionally, the results indicated that the optimal conditions for good formation of wet adhesive is $1(\mathrm{~g})$ of PVP-PI to $2 \mathrm{~g}$ ) of OA. Moreover, the optimum irradiation dose for the highest adhesion force is 20 kGy. The adhesion force was tested versus time ranged from 1 to 460 day. The results indicated to high goodness of samples. Furthermore, the adhesion force was tested versus temperature ranged from 4 to $35^{\circ} \mathrm{C}$. The results referred to good stability of samples. The synthesized wet adhesives were exploited to attract and trap the flies and mosquitoes. The results illustrated good efficiency of wet adhesives to attract and trap the flies and mosquitoes as well. Therefore, these wet adhesives may be used in industrial field with mass production. Finally, it can be concluded that this kind of work need further study and series of works in this point specifically to explore more about the formed materials and their different applications.

\section{Declarations}

\section{Acknowledgements}

This publication was supported possible by Academy of Scientific Research and Technology (ASRT), Technology Innovation Commercialization Office (TICO) through Grant Number 29". The statements made herein are solely responsibility of the authors. Technical support from the Department of Polymer Chemistry, Central Laboratory Unit, National Centre for Radiation Research and Technology at Egyptian Atomic Energy Authority is also acknowledged.

Supplementary Information The online version contains supplementary material available at https://doi.org/.

\section{Declaration Conflict of interest}

The authors declare that they have no conflict of interest.

\section{References}

1. Lee L-H (2013) Fundamentals of Adhesion, Springer Science \& Business Media, New York. https://doi.10.1007/978-1-4899-2073-7

2. Yang J, Bai R, Chen B, Suo Z (2019) A Supramolecular synergy of chemistry, topology, and mechanics. Adv Funct Mater 30:e1901693. https://doi. 10.1002/adfm.201901693

3. Yuk H, Lin S, Ma C, Takaffoli M, Fang NX, X. Zhao X (2017) Hydraulic hydrogel actuators and robots optically and sonically camouflaged in water. Nat Commun 8:14230. https://doi.10.1038/ncomms14230

4. Zhao Y, Wu Y, Wang L, Zhang M, Chen X, Liu M, Fan J, Liu J, Zhou F, Wang Z (2017) Bio-inspired reversible underwater adhesive. Nat Commun 8:2218. https://doi.10.1038/s41467-017-02387-2

5. Annabi N, Yue KA,Tamayol A, Khademhosseini A (2015) Elastic sealants for surgical applications. Eur J Pharm Biopharm 95:27-39. https://doi. 10.1016/j.ejpb.2015.05.022 
6. Li L, Celiz AD, Yang J, Yang Q, Wamala I, Whyte W, Seo BR, Vasilyev NV, Vlassak JJ, Suo Z (2017) Tough adhesives for diverse wet surfaces. Science 357:378-381.

https://doi.10.1126/science.aah6362

7. Yuk H, Zhang T, Lin S, Parada GA, X. Zhao X (2016) Tough bonding of hydrogels to diverse nonporous surfaces. Nat Mater 15:190-196. https://doi. 10.1038/nmat4463

8. Rose S, Prevoteau A, Elzière P, Hourdet D, Marcellan A, Leibler L (2014) Nanoparticle solutions as adhesives for gels and biological tissues. Nature 505:382-385. https://doi.10.1038/nature12806

9. Rouse Jr PE (1953) A theory of the linear viscoelastic properties of dilute Solutions of coiling polymers. J Chem Phys 21:1272-1280. https://doi. 10.1063/1.1699180

10. Quinn JV (2005) Tissue adhesives in clinical medicine, Decker Inc., Hamilton. https://www.worldcat.org/title/tissue-adhesives-in-clinical-medicine/oclc/58597655

11. Hooke R (1965) Micrographia. London.https://www.bl.uk/collection-items/micrographia-by-roberthooke-1665

12. Drechsler, W. Federle W (2006) Biomechanics of smooth adhesive pads in insects: influence of tarsal secretion on attachment performance. J Comp Physiol A 192:1213-1222. https://doi.

10.1007/s00359-006-0150-5

13. Beutel RG, Gorb SN (2001) Ultrastructure of attachment specializations of hexapods (Arthropoda): evolutionary patterns inferred from a revised ordinal phylogeny. J Zool Syst Evol Res 39:177-207. https://doi.10.1046/j.1439-0469.2001.00155.x

14. Eisner T, Aneshansley DT (2000) Defense by foot adhesion in a beetle (Hemisphaerota cyanea). Proc Nat Acad Sci USA 97:6568-6573. https://doi. 10.1073/pnas.97.12.6568

15. Federle W, Brainerd EL, McMahon TA, B. Hölldobler B (2001) Biomechanics of the movable pretarsal adhesive organ in ants and bees. Proc Nat Acad Sci USA 98:6215-6220. https://doi. 10.1073/pnas. 111139298

16. Federle W, Riehle M, Curtis ASG, Full RJ (2002) An integrative study of insect adhesion: mechanics and wet adhesion of pretarsal pads in ants. Integr Comp Biol 421:100-1106. https://doi.10.1093/icb/42.6.1100

17. Waite JH (1987) Nature's underwater adhesive specialist. Int J Adhes Adhes 7:9-14. https://doi. 10.1016/0143-7496(87)90048-0

18. Yang J, Bai R, Suo Z (2018) Topological adhesion of wet materials. Adv Mater 30:e1800671. https://doi. 10.1002/adma.201800671

19. Mao X, Yuk H, Zhao X (2020) Hydration and swelling of dry polymers for wet adhesion. J Mech Phys Solids 137:103863. https://doi. 10.1016/j.jmps.2020.103863

20. Dafader NC, Adnan MN, Haque ME, Huq D, Akhtar F (2011) Study on the properties of copolymer hydrogel obtained from acrylamide/2-hydroxyethyl methacrylate by the application of gamma radiation. Afr J Pure Appl Chem 5:111-118. https://doi.10.5897/AJPAC.9000146 
21. Becerra-Bracamontes F, Sanchez-Diaz JC, Gonzalez-Alvarez A, Ortega-Gudino P, Michel-Valdivia E, Martinez-Ruvalcaba A (2007) Design of a drug delivery system based on poly(acrylamide-co-acrylic acid)/chitosan nanostructured hydrogels. J Appl Polym Sci 106:3939-3944. https://doi.10.1002/app.26992

22. Fei B, Wach RA, Mitomo H, Yoshii F, Kume T. Hydrogel of biodegradable cellulose derivatives. J Appl Polym Sci 2000;78:278 - 283. https://doi. 10.1002/app.1753

23. Jabbari E, Nozari S (2000) Swelling behavior of acrylic Acid hydrogels prepared by gamma-radiation cross-linking of polyacrylic acid in aqueous solution. Eur Polym J 36:2685 - 2692. https://doi.10.1016/S0014-3057(00)00044-6

24. Lim LS, Rosli NA, Ahmad I, Lazim AM, Mohd Amin MCl (2017) Synthesis and swelling behavior of pH-sensitive semi-IPN superabsorbent hydrogels based on poly (acrylic acid) reinforced with cellulose nanocrystals. Nanomaterials 7:399. https://doi.10.3390/nano7110399

25. Rosiak JM, P. Ulanski P (1999) Synthesis of hydrogels by irradiation of polymers in aqueous solution. Radiat Phys Chem 55:139-151. https://doi. 10.1016/S0969-806X(98)00319-3

26. Foroutan H, Khodabakhsh M, Rabbani M (2007) Investigation of synthesis of PVP hydrogel by irradiation. Iran J Radiat Res 5:131-136. http://ijrr.com/article-1-326-en.html.

27. Wojtkowski PA (2008) Agroecological Economics: Sustainability and Biodiversity, first edition, Academic Press. https://www.sciencedirect.com/book/9780123741172/agroecological-economics

28. Kaloostian GH (1961) Evaluation of adhesives for sticky board traps. J Econ Entomol 54:1009-1011. https://doi.10.1093/jee/54.5.1009

29. Chin H, Sallehudin S, Fathi OH (2008) Evaluation of neopeace, neopeaceF101, and malaysia assurance rats glue for trapping musca domestica (diptera:muscidae) in the field. J Trop Med Parasitol 31:1-5. http://www.caht.ca/evaluation-of-the-humaneness-of-rodent-capture-using-gluetraps/

30. Ryan L, Molyneux DH (1981) Non-setting adhesives for insect traps. Sci Appl 1:349-355. https://www.cabdirect.org/cabdirect/abstract/19822902577

31. Webb R, Smith F, Affeldt H, Thimijan R, Dudley R, Webb H (1985) Trapping greenhouse whitefly with coloured surfaces: Variables affecting efficacy. Crop Prot 4:381-393. https://doi.10.1016/02612194(85) 90042-0

32. Hall DG, Hentz MG (2010) Sticky trap and stem-tap sampling protocols for the asian citrus psyllid (hemiptera: psyllidae). J Econ Entomol 103:541-549. https://doi.10.1603/ec09360

33. Yee WL (2011) Evaluation of yellow rectangle traps coated with hot melt pressure sensitive adhesive and sticky gel against rhagoletis indifferens (Diptera: Tephritidae). J Econ Entomol 104:909-919. https://doi.10.1603/EC10327

34. Garoushi S, Vallittu PK, Lassila LVJ (2007) Short glass fiber reinforced restorative composite resin with Semi-inter penetrating polymer network matrix. Dent Mater 23:1356-1362. https://doi.10.1016/j.dental.2006.11.017 
35. Nájera JJ, Horn AB (2009) Infrared spectroscopic study of the effect of oleic acid on the deliquescence behaviour of ammonium sulfate aerosol particles. Chem Phys. 11:483-494. https://doi.10.1039/B812182F

36. Rahma A, Munir MM, Khairurrijal MM, Prasetyo A, Suendo V, Rachmawati H (2016) Intermolecular interactions and the release pattern of electrospun curcumin polyvinyl(pyrrolidone) fiber. Biol Pharm Bull 39:163-173. https://doi.10.1248/bpb.b15-00391

37. Chiantore O, Guaita M, Lazari M, Hadjichristidis N, Pitsikalis M (1995)

Thermal-degradation of model linear and star-shaped polyisopyrene molecules. Polym Degrad Stab 49:385. https://doi.10.1016/0141-3910(95)00119-7

38. Cibulková Z, Polovková J, Luke V, Klein E (2006) DSC and FTIR study of the gamma radiation effect on Cis-1,4-polyisoprene. J Therm Anal Calorim 84:709-713. https://doi.10.1007/s10973-005-7547-1

39. Kadajji VG, Betageri VB (2011) Water soluble polymers for pharmaceutical applications. Polymers 3:1972-2009. https://doi. 10.3390/polym3041972

40. Wang Z, Zhang Y, Jiang F, Fang H, Wang Z (2014) Synthesis and characterization of designed cellulose-graft-polyisoprene copolymers. Polym Chem 5:3379-3388. https://doi. 10.1039/C3PY01574B

41. Breuer B, Fock HP (1987) Separation of fatty acids or methyl esters including positional and geometric isomers by alumina argentation thin-layer chromatography. J Chromatogr Sci 25:302-306. https://doi. 10.1093/chromsci/25.7.302

42. Tucci ER (1966) Separation and recovery of triethylaluminum from normal alpha-olefins. Ind Eng Chem Prod Res Dev 5:161-165. https://doi. 10.1093/chromsci/25.7.302

43. Du KK, Yang IP, Mou ZG, Hua NP, Jiang L (2006) Thermal decomposition behaviors of PVP coated on platinum nanoparticles. J Appl Polym Sci 99:23. https://doi. 10.1021/i360018a014

\section{Figures}




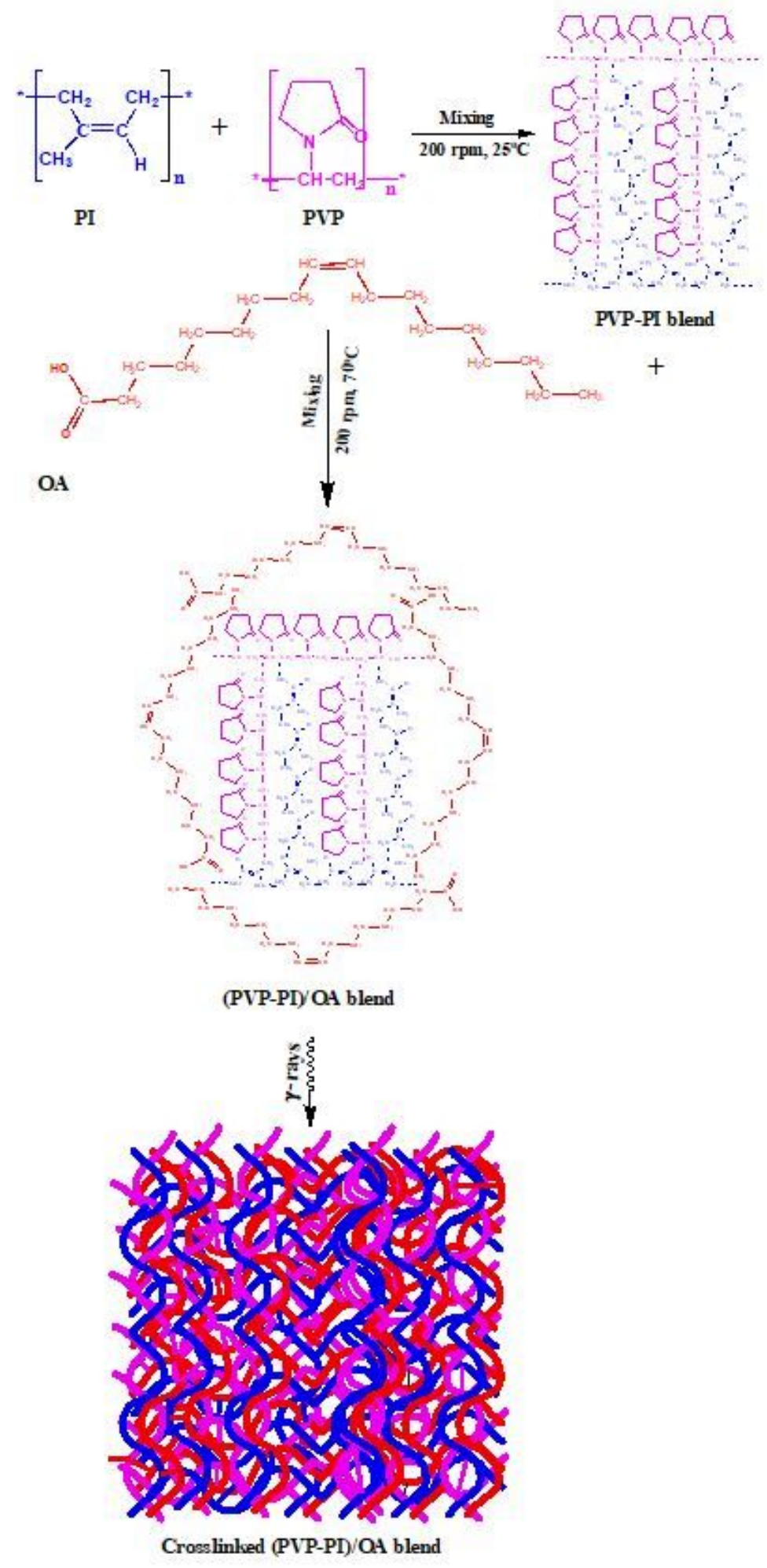

Figure 1

A proposed schematic diagram for the synthesis of homogenous and crosslinked PVP, PI and OA blend via using the subsequent mixing processes followed by exposure to $\gamma$-rays. 

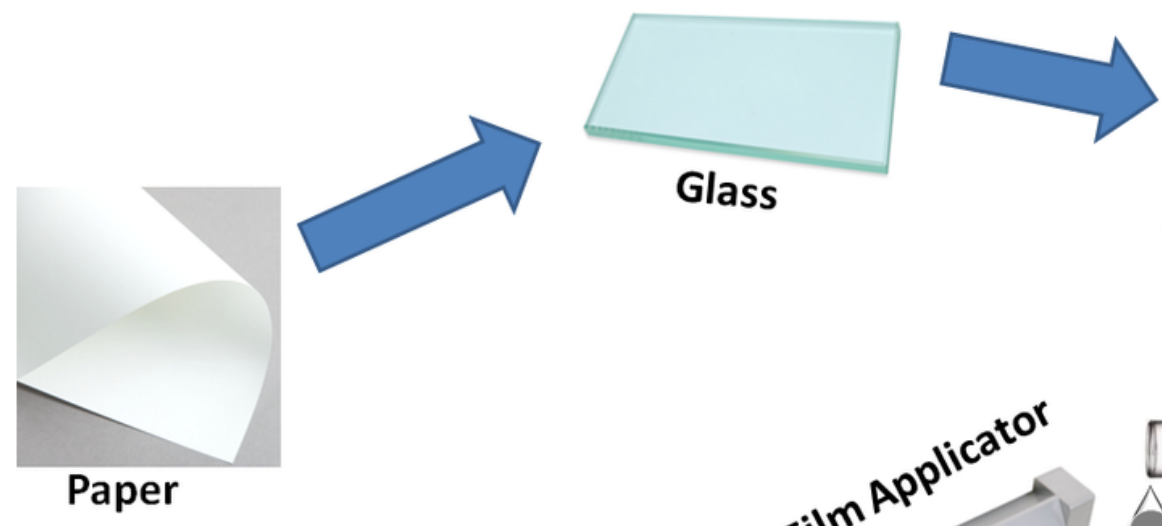

\section{Glass}
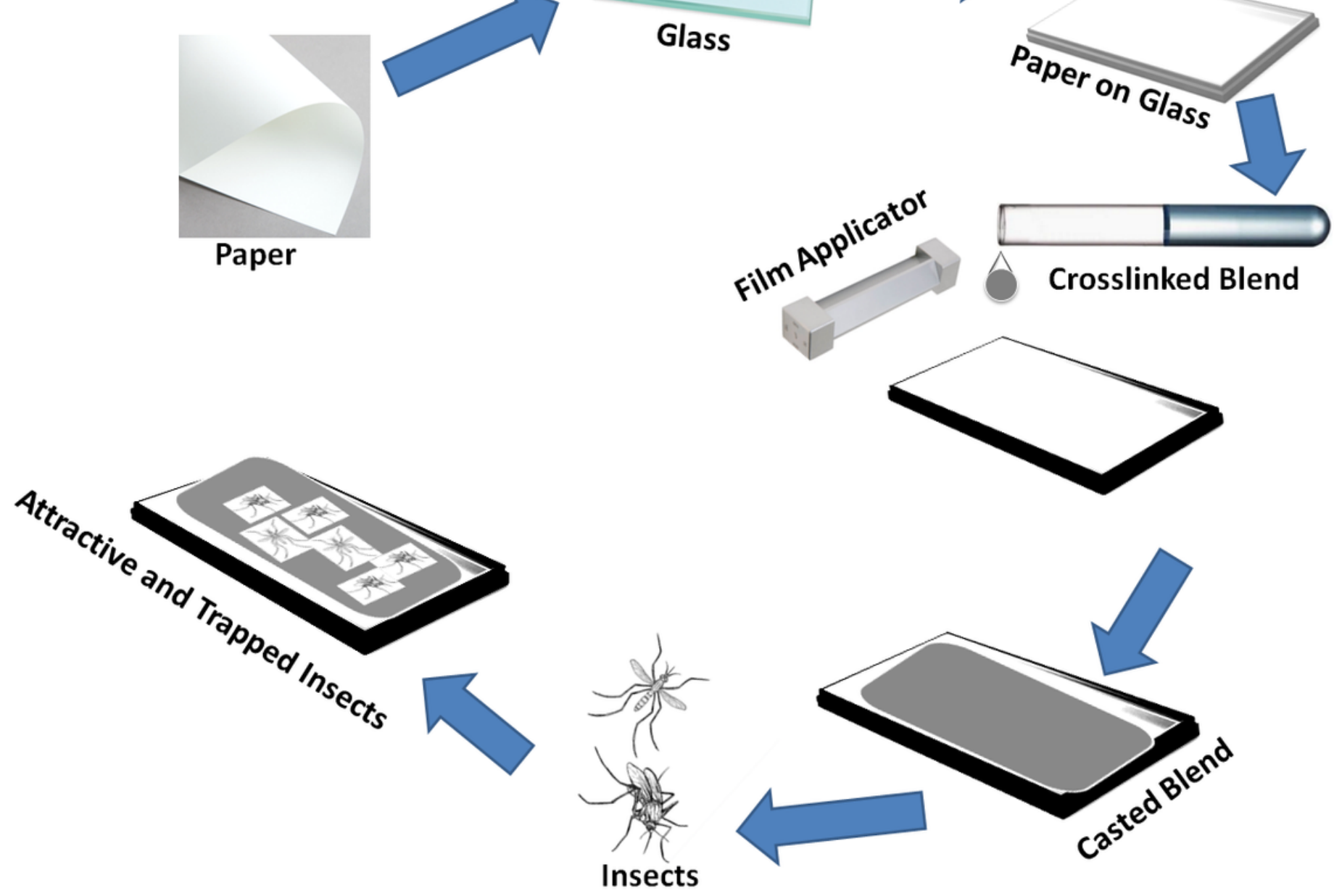

Figure 2

Shows the set-up of casting process of crosslinked (PVP-PI)/OA blend, attract and trapping insects. 


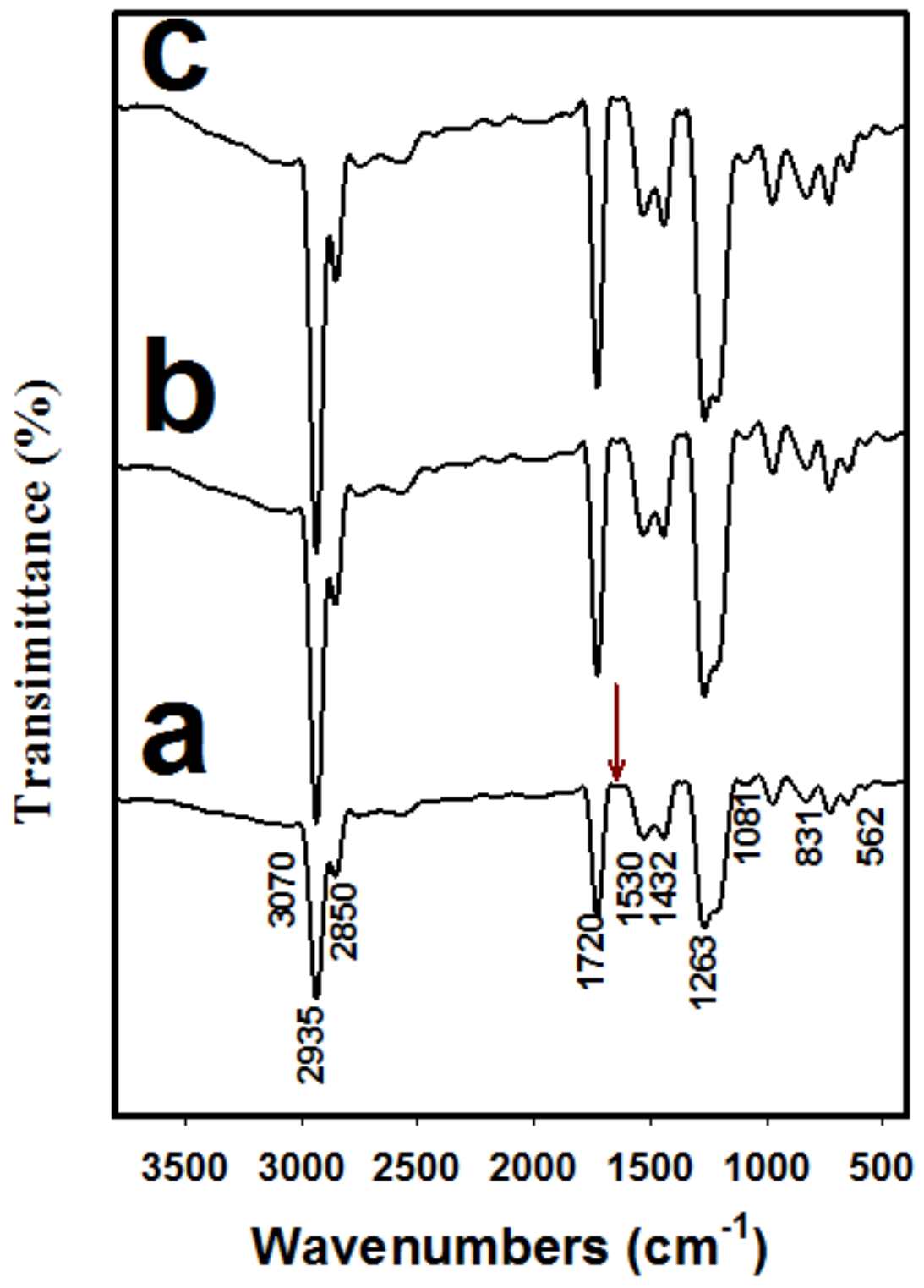

Figure 3

Shows the FTIR spectra of three compositions of crosslinked (PVP9-PI1)/OA blends (a) 2:1. (b) 1:1 and (c) $1: 2(\mathrm{~g} / \mathrm{g})$, respectively at exposure irradiation dose is $30 \mathrm{kGy}$ of irradiation dose rate is $\sim 2.2 \mathrm{kGy} / \mathrm{h}$. 


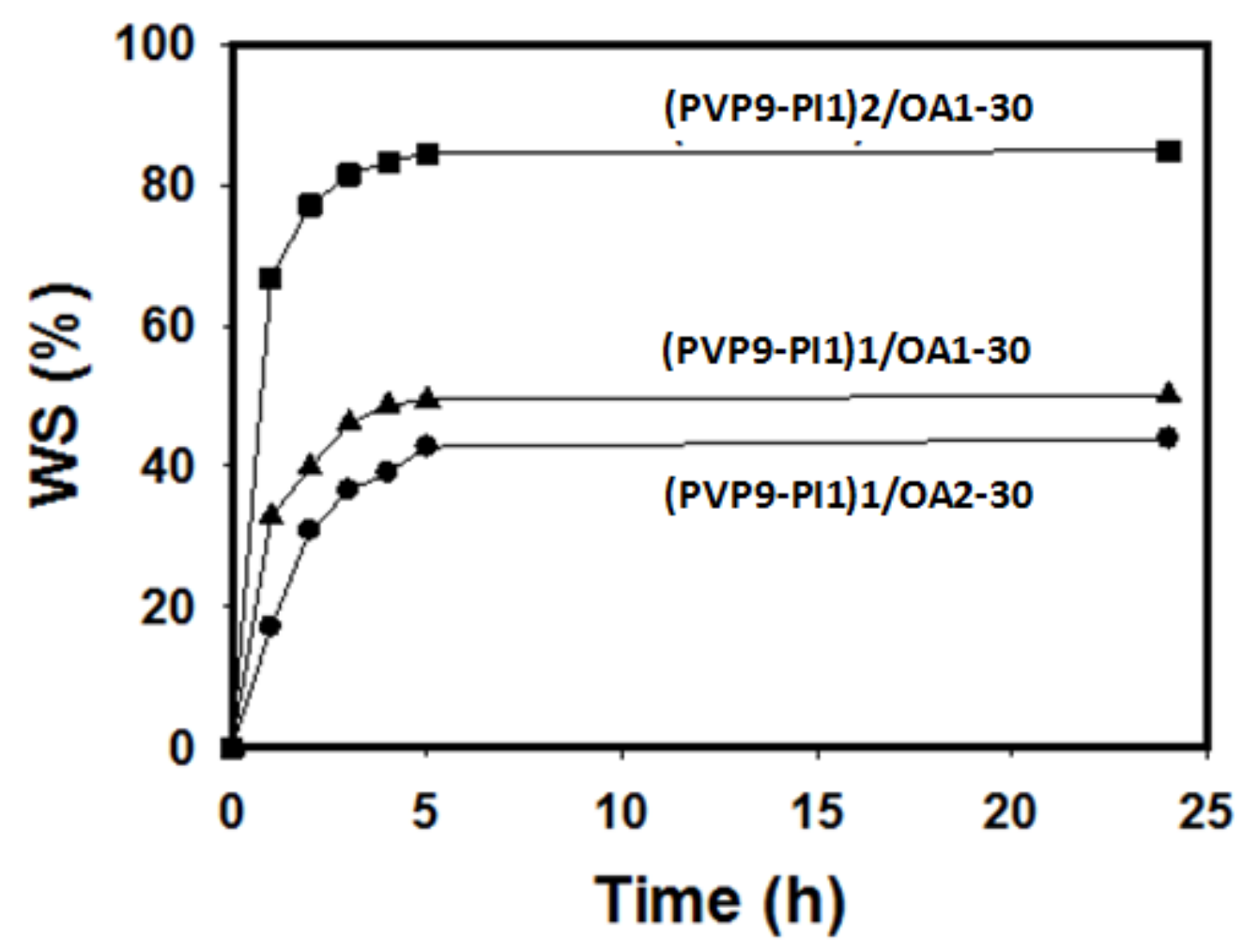

Figure 4

Shows the time (h) versus WS (\%) of three compositions of crosslinked (PVP9-PI1)/OA blends; 2:1, 1:1 and 1:2 $(\mathrm{g} / \mathrm{g})$, respectively at exposure irradiation dose is $30 \mathrm{kGy}$ of irradiation dose rate is $\sim 2.2 \mathrm{kGy} / \mathrm{h}$.

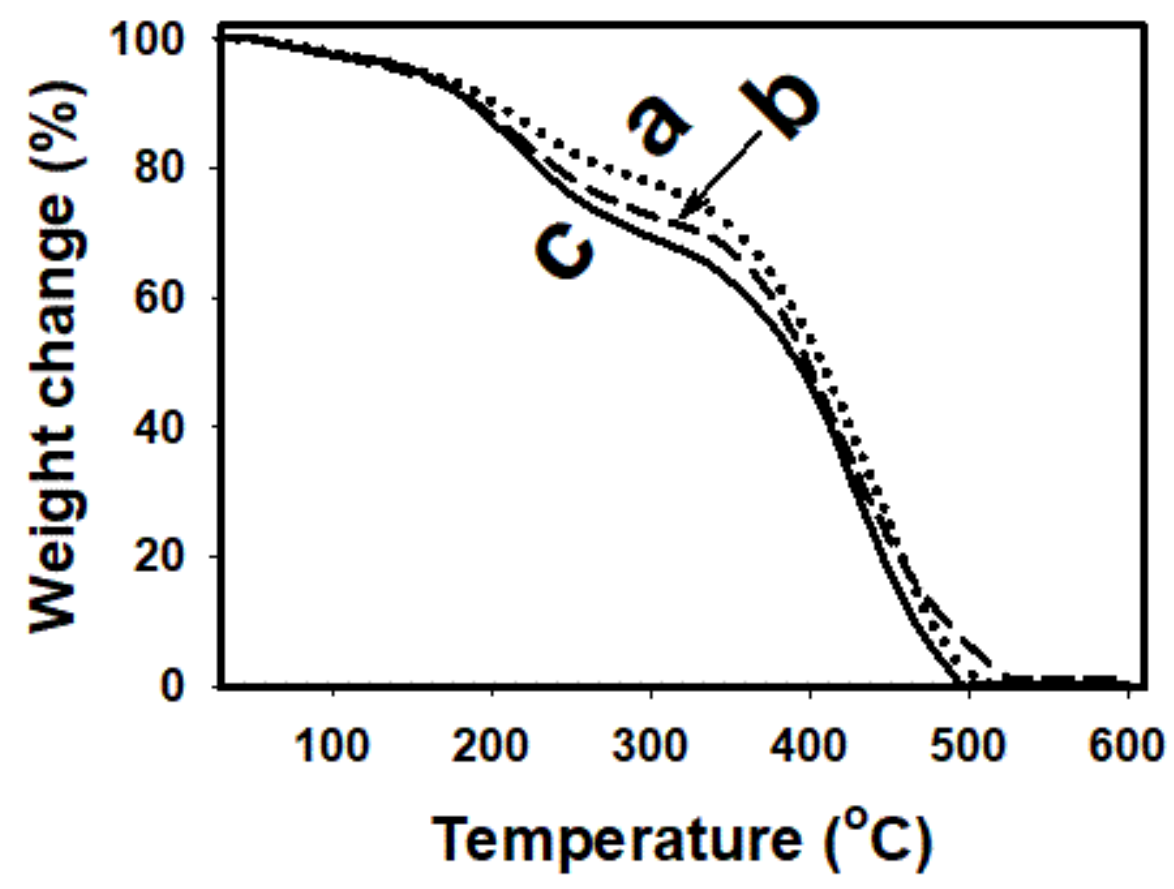

Figure 5 
Illustrates TGA thermograms of three compositions of crosslinked (PVP9-PI1)/OA blends at (a) 2:1. (b) $1: 1$ and $(\mathrm{c}) 1: 2(\mathrm{~g} / \mathrm{g})$, respectively at exposure irradiation dose is $30 \mathrm{kGy}$ of irradiation dose rate is $\sim 2.2$ $\mathrm{kGy} / \mathrm{h}$.
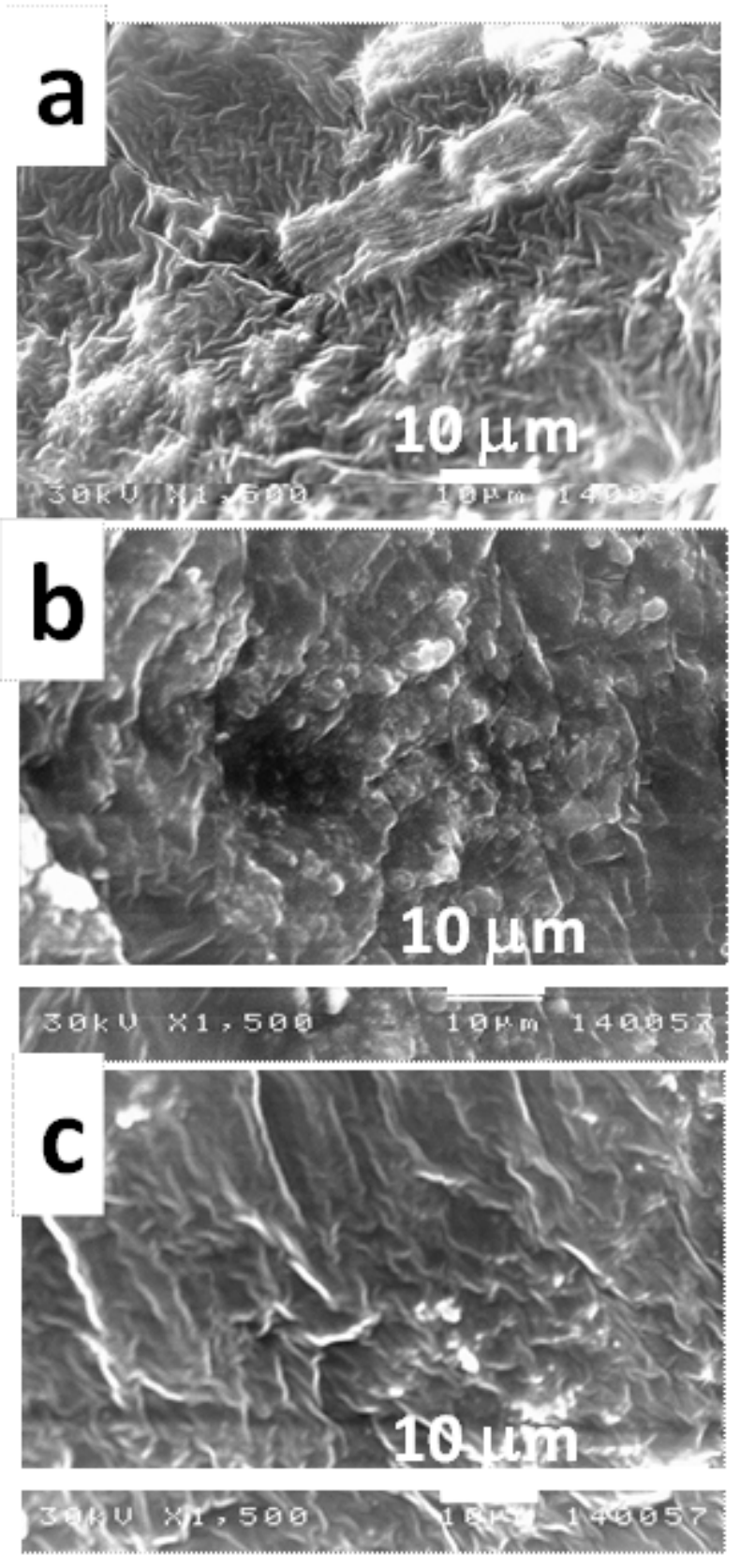

\section{Figure 6}

Shows SEM photomicrographs of three compositions of crosslinked (PVP9-PI1)/OA blends at (a) 2:1. (b) $1: 1$ and $(\mathrm{c}) 1: 2(\mathrm{~g} / \mathrm{g})$, respectively at exposure irradiation dose is $30 \mathrm{kGy}$ of irradiation dose rate is $\sim 2.2$ $\mathrm{kGy} / \mathrm{h}$. 


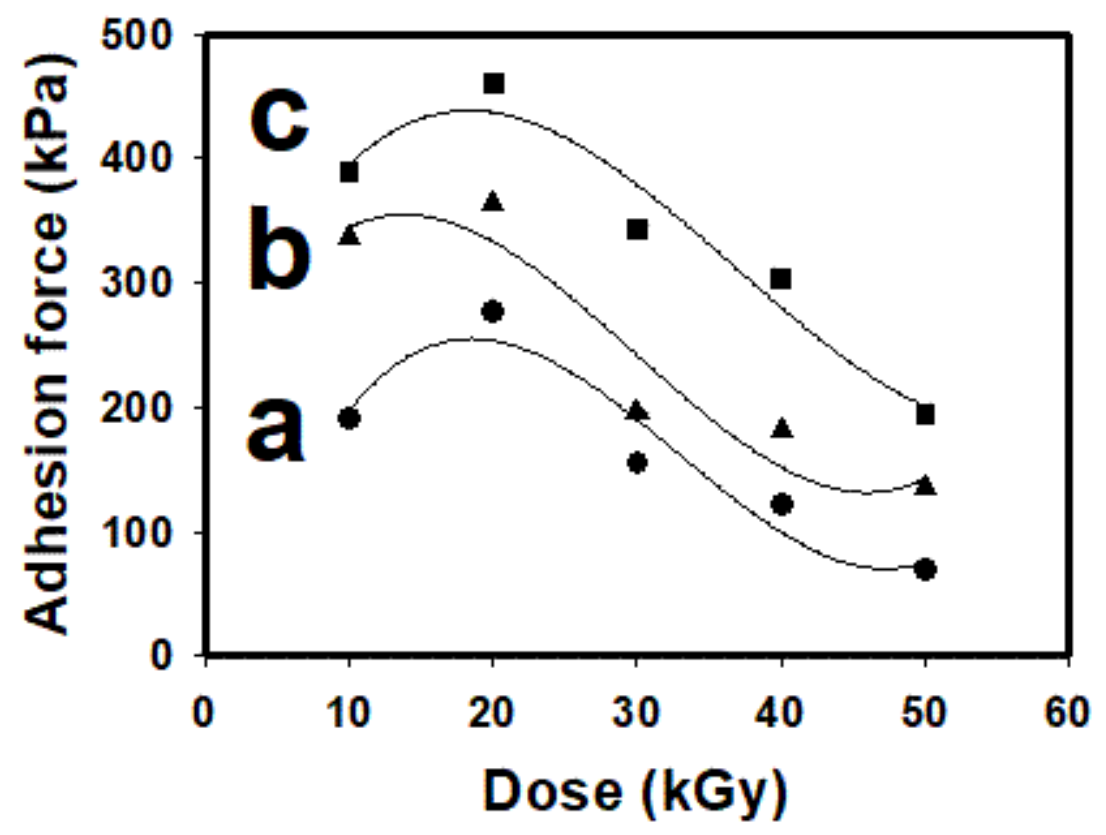

Figure 7

Shows adhesion force of three compositions of crosslinked (PVP9-PI1)/OA blends at (a) 2:1. (b) 1:1 and (c) $1: 2(\mathrm{~g} / \mathrm{g})$, respectively and irradiation dose rate is $\sim 2.2 \mathrm{kGy} / \mathrm{h}$. 

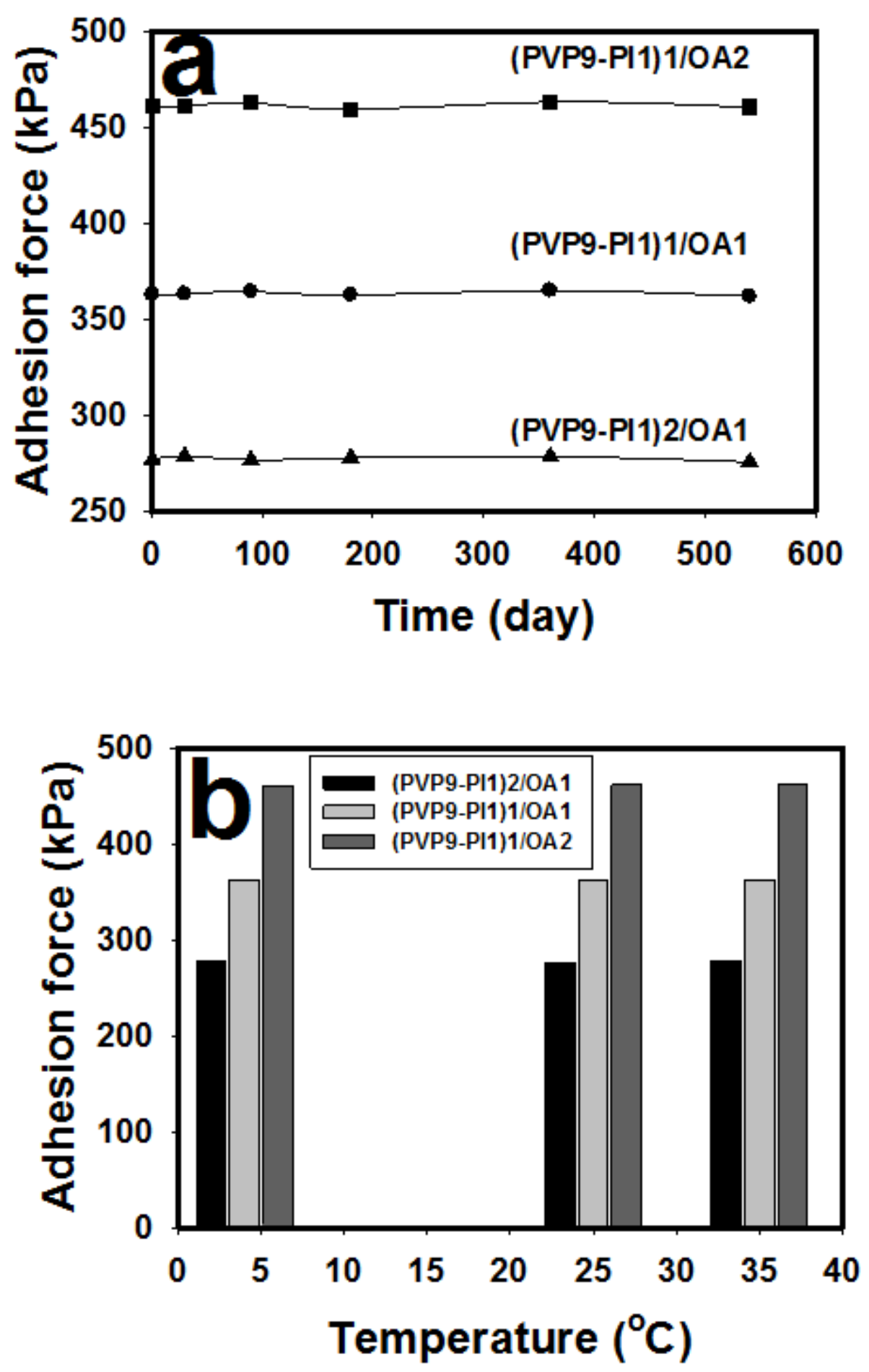

Figure 8

(a) adhesion force of three compositions of crosslinked (PVP9-PI1)/OA blends at 2:1, 1:1 and (c) 1:2 $(\mathrm{g} / \mathrm{g})$ versus time and $(\mathrm{b})$ adhesion force of three compositions of crosslinked (PVP9-PI1)/OA blends at 2:1, 1:1 and (c) 1:2 (g/g) versus temperature. Irradiation dose $20 \mathrm{kGy}$ and rate is $\sim 2.2 \mathrm{kGy} / \mathrm{h}$. 

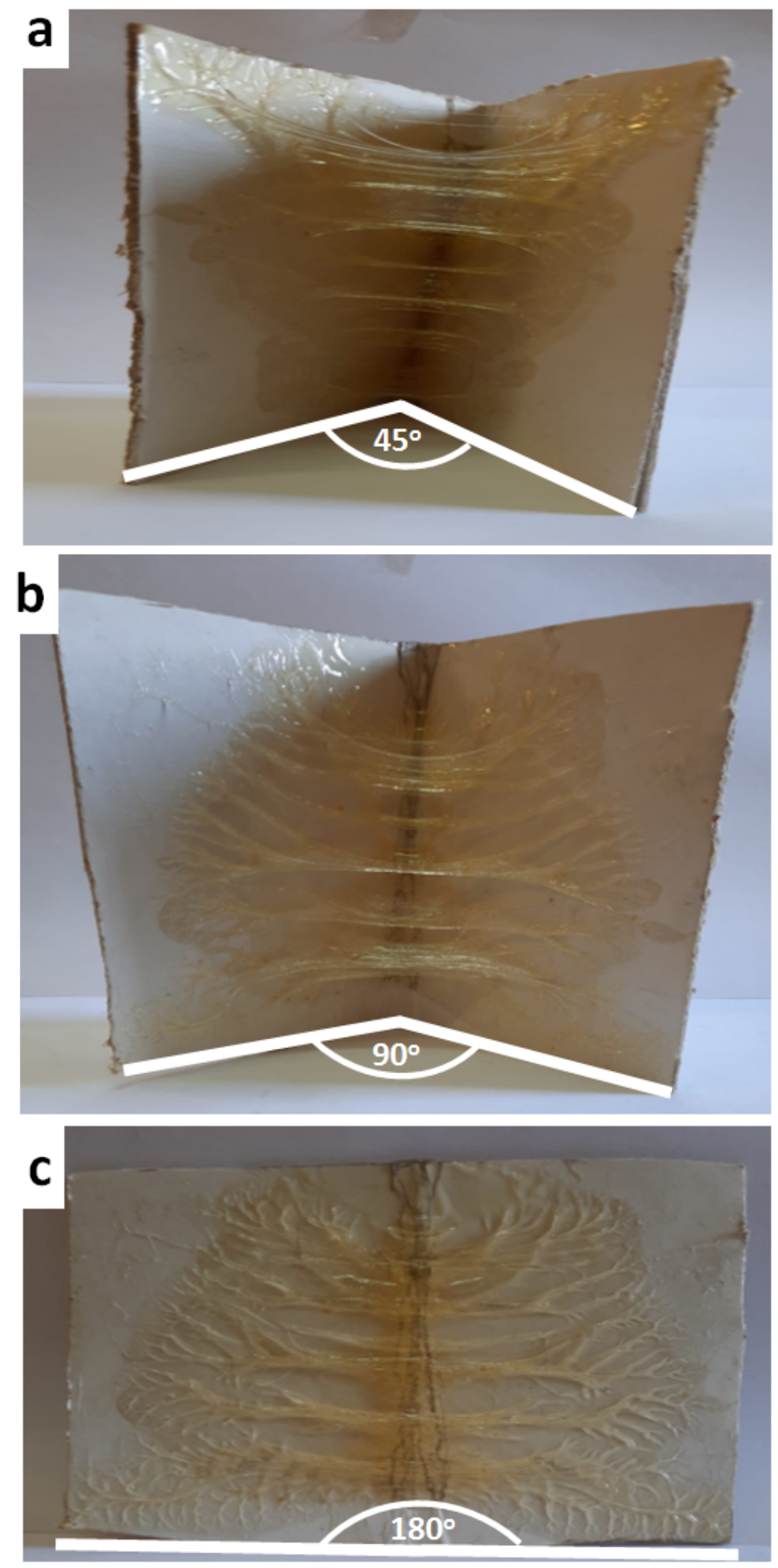

Figure 9

Shows the photos of adhesion force of crosslinked (PVP9-PI1)/OA blends at1:2 $(\mathrm{g} / \mathrm{g})$ at different angles (a) 45o, (b) 90o and (c) 180o, respectively for composition of crosslinked (PVP9-PI1)/OA blends at 1:2 $(\mathrm{g} / \mathrm{g})$,irradiation dose $20 \mathrm{kGy} / \mathrm{h}$ and irradiation dose rate is $\sim 2.2 \mathrm{kGy} / \mathrm{h}$. 


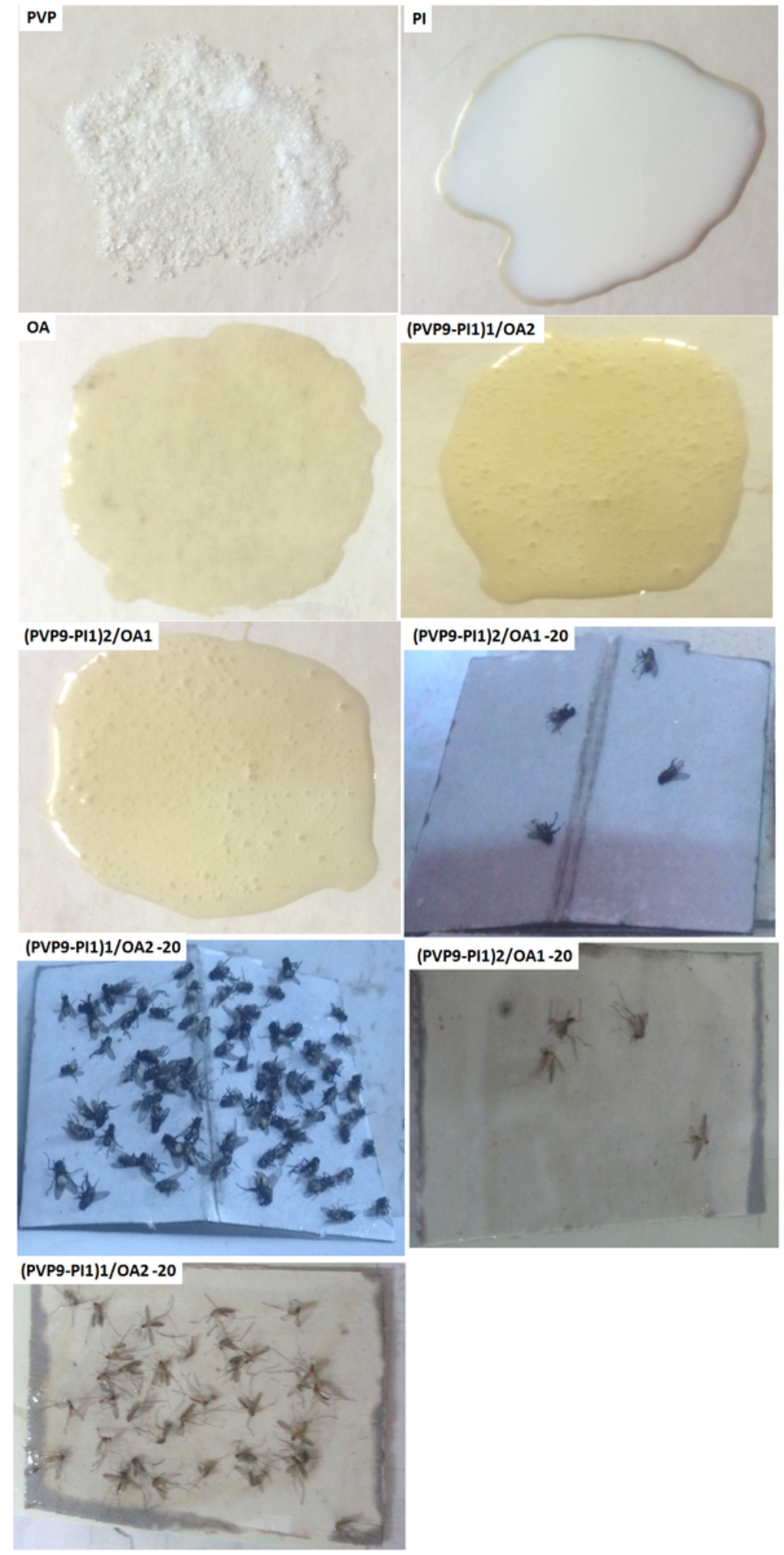

Figure 10

Shows the photos of attraction and trapping of flies and mosquitoes using different samples.

\section{Supplementary Files}

This is a list of supplementary files associated with this preprint. Click to download. 
- SupplementaryDataFile1.docx

Page 23/23 